\title{
SAFETY VALUATION METHODS AT URBAN ATYPICAL INTERSECTIONS. ANALYSIS OF INFRASTRUCTURAL SCENARIOS
}

\author{
A. GRANÀ \\ Department of Road Infrastructure Engineering, Palermo University, Italy.
}

\begin{abstract}
The definition of decision support tools for identifying ex ante evaluation issues for road safety measures is a new challenge for policymakers and designers managing road networks with the intention of improving traffic safety for roads of their competence. This is consistent with explicit strategies on sustainability in the transport sector established at European level, considering road safety as an essential prerequisite to warrant a sustainable mobility. Based on these considerations, the need for evaluation instruments of safety conditions both for existing infrastructural schemes and for new road installations is recently arisen so that the identification of risks involved in a particular road infrastructure is easier, as well as the definition of the priorities of intervention by means of technical measures. This is true in particular for road junctions characterized by a configuration not conforming to those ones recognized as safer. On this regard, the results of safety evaluations at roundabouts are not an exhaustive reference for geometric design where organizational schemes for circular intersections are similar to roundabouts but resulting from compromise choices as regards one or more geometric features of the roundabout. For this kind of atypical intersections specific safety problems are found, particularly in urban areas, due to existing constraints of different kind and the great variety of geometric layouts they take on. Moreover, in these cases the possibility of applying the safety methods proposed in the literature regarding traditional roundabouts, as well as the road safety audit procedures, is also compromised. Based on these considerations, in this paper ten case studies of this kind of intersections have been examined in order to verify the effectiveness of the risk analysis proposed by means of an infrastructural scenarios method. From the methodological point of view, the application of the accident delocalization procedure has allowed to highlight in relative terms the riskiness of different infrastructural scenarios arranging the organizational schemes of intersections. Moreover, the proposed method can represent a useful tool for safety diagnostic analysis being able to provide informations for policymakers and designers in order to address the infrastructural scenarios and the road schemes that need to be tested.
\end{abstract}

Keywords: circular intersection, infrastructural scenario, risk analysis, road safety, roundabout.

\section{INTRODUCTION}

Road traffic conditions more and more the quality of life for the communities and significantly contributes to the damage to the environment. In particular, road crashes and their results as regards deaths, disabilities, welfare and social costs, and the air and noise pollution in urban area are the most evident events perceived by all the people. As road transport activity, both in urban areas and in rural ones, continues to increase, EU policymakers are trying to develop policies of 'sustainable mobility' [1,2] in order to rationalize transport activities. In this regard the EU Commission in its 2001 White Paper on Transport Policy [3] has also outlined explicit strategies on sustainability in the transport sector; these strategies focus predominantly on: i) balancing the different modes of transport; ii) harmonizing legislation within specific sectors; and iii) improving transport safety and road infrastructures. In particular, the road safety is defined in the European Road Safety Action Programme [4] as an essential prerequisite to warrant a sustainable mobility; in fact, both improvements for road infrastructures and the definition of procedures directed towards the reduction of the frequency and seriousness of road traffic accidents are regarded among the main areas of action. By these considerations, designers can influence road user behaviors giving road installations an explicit 
configuration; furthermore, the creation of a forgiving road environment so that human error does not necessarily end in serious injuries should make for safer roads.

So, on several occasions, stakeholders and road engineers have called for systematic safety impact assessments as regards new infrastructural installations, improvements needed to the existing road network and guidelines to be drawn up for the implementation of low-cost road safety countermeasures and the carrying-out of road safety audits [5-8].

As indicated in the above mentioned White Paper, when new road projects or the improvements needed to the existing network are examined, a safety impact assessment should be carried out to guarantee that the road installations will not have adverse effects on safety in the examined area.

In order to contribute to the development of an inherently safe road traffic system it's necessary to develop a common and integrated approach for identifying ex-ante evaluation issues of road safety [9]. To reduce the proportion of high-risk existing roads and to prompt users to drive more carefully, it's also necessary to establish supportive analytical tools for use by safety professionals about the identification of risks involved in a particular road infrastructure (i.e. stretch of road or intersection).

Consistent with the need for methods and tools for identifying risk related to specific road installations, in this paper a method of risk analysis that can be used to establish the risk entity of particular road intersections is proposed. The approach is applied to circular intersections sited in urban area and characterized by existing constraints that have conditioned both geometric features and traffic conditions; this is why safety methods proposed in technical literature aren't often applicable to atypical geometric schemes. The research intends to explore the accident phenomenology at this kind of intersections and proposes an approach necessary to identify the priorities to be respected for engineering interventions concerning road safety.

\section{THE BACKGROUND OF THIS RESEARCH}

The application of a procedure of preventive safety analysis (road safety review) to existing roads suggests that the case under examination is comparable to similar situations of which the corresponding risk level is known or foreseeable. The effectiveness of the preventive evaluation, resulting from experiences and qualifications of the auditor team, therefore is highly conditioned by possibilities to transfer to case studies all that is known as regards road safety for the type of corresponding infrastructural sistemation (i.e. type of road or type of intersection). These assumptions, nevertheless, slowly decline in urban areas where road installations are characterized by features quite peculiar due to the presence of different types of constraints that impose both adaptations and, in some case, forces to schemes characterized by optimal operations.

The highlighted circumstance assumes particular importance at junctions, where operational conditions, quite different due to local features that have conditioned their installations in urban area, can correspond with a similar organizational pattern (type of intersection). This is a serious impediment for applying wide scale preventive control procedures, as those adopted for a long time in other countries [5-7] and only for a short time [8] in Italy; this has the opposite effect considering that 2/3 of urban accidents happened at junctions and these are the most sensitive elements of urban road network as regards the accident reduction, considering engineering improvements targeted to optimize road safety conditions.

\section{THE OBJECTIVES AND THE ARTICULATION OF THE RESEARCH}

Based on these considerations, a research of atypical circular intersections have been conceived and carried out in order to determine a safety criterion for infrastructural schemes characterized by geometric and functional features not necessarily conformable to good roundabout design and not always directly referable to road situations of which, based on previous studies, risk levels are known. 

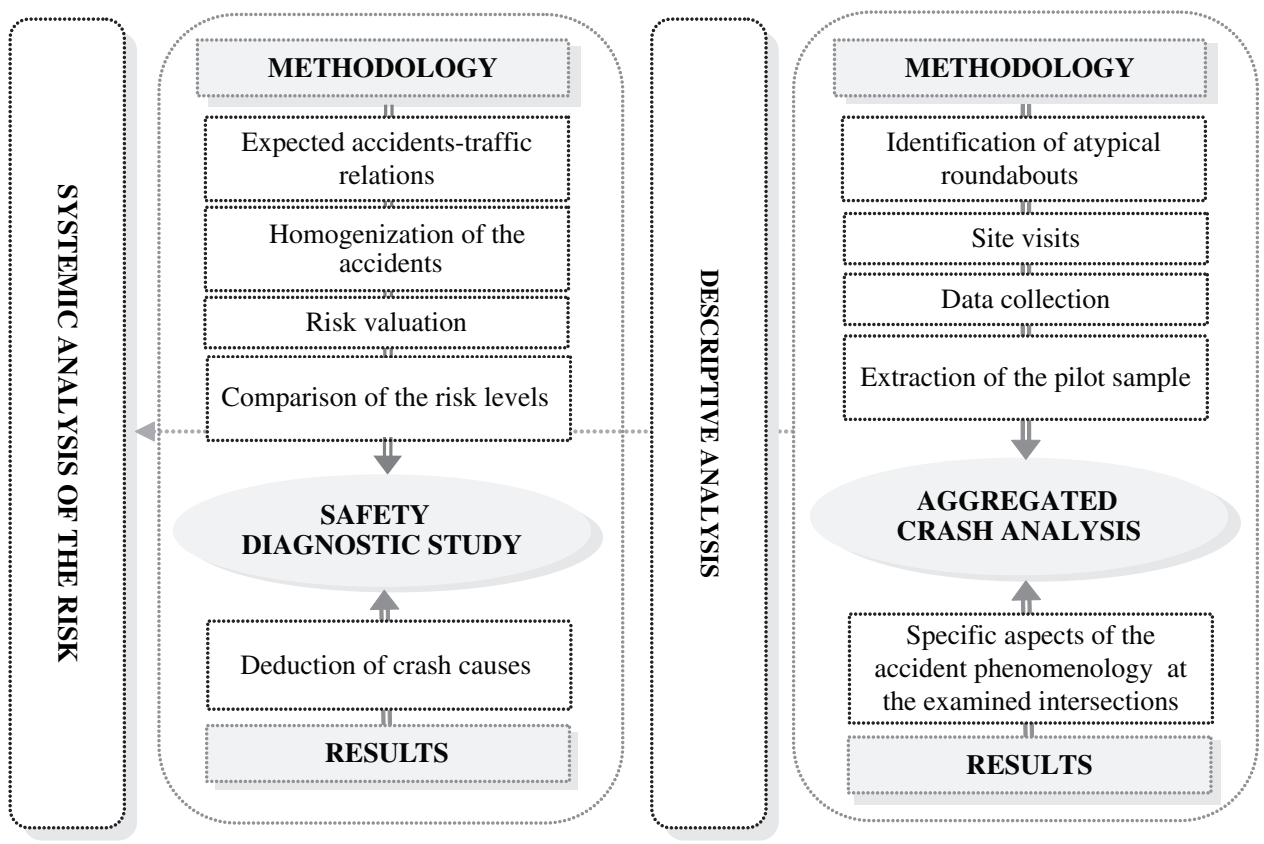

Figure 1: The flowchart of the systemic analysis of the risk.

The study has been developed as from field observations with regard to organizational schemes for junctions characterized by a geometric design referable to roundabouts but conditioned by the existing constraints of different kind (particularly physical and topographical ones) that require quite different driving behaviours from those that are observable at conforming roundabouts.

As regards the above mentioned aims, the accident phenomenology analysis of this kind of notconforming road schemes has been organized into two phases:

- the aggregate analysis in order to explain specific aspects of road safety and the accident phenomenology at examined not-conforming roundabouts;

- the safety diagnostic study based on a delocalization procedure as regards the infrastructural scenarios existing in the examined intersections, in order to devise a risk model suitable for valuing the riskiness of different not-conforming roundabouts.

The study has been preceded by a wide research of studies proposed in the literature regarding urban safety at roundabouts [10-14] in order to know the accident features of the examined intersections. The risk analysis by means of an infrastructural scenarios method has been carried out through the logic phases shown in Figure 1.

\subsection{The sample choice and data collection}

\section{RESULTS OF AGGREGATED ANALYSIS}

The first phase of the research is characterized by the identification of a sample of not-conforming roundabouts to analyze. For this purpose, in Palermo City network the intersections referable to roundabouts have been identified both for geometric layout and for traffic conditions; each one of them has been characterized from the point of functional-geometric view by means of the medium radius of central island, the ring width and the number of arms. 
From these explored intersections a pilot sample representative of the not-conforming roundabouts has been extracted. For each element of the sample a check of the geometric characteristics has been carried out on field. Then the accident data for the period 1996-2000 have been collected directly from records of municipal police force, considering both personal injury crashes and damage only; for each accident the date and the time have been recorded, as well as further specific aspects as collision types, the crash location, types of accident-causing factors, type and number of users, weather conditions, dynamics of the accident, etc. Considering that both in under-saturated traffic conditions and in traffic conditions close to capacity the circulating traffic influences the entering flows, accidents that occurred along the arms for $20 \mathrm{~m}$ up to the stop line have been registered as occurred in roundabout, too.

The traffic scenario has been represented combining available data to sample observations suitably planned for each element of the pilot sample. Traffic surveys have been characterized by three repetitions during working days (Tuesday, Wednesday, Thursday) of four hours during the day. The hourly values have been calculated as the average of $15 \mathrm{~min}$ flows.

A sample of 655 crashes, of which $1 / 3$ was characterized by personal injury accidents, from ten urban circular intersections in Palermo City for the period 1996-2000 have been examined.

\subsection{The factors of the analysis}

The aggregated analysis has been developed as regards all accidents including injury accidents, in order to obtain a representation of the accident phenomenon independent of accident severity (this, in particular in urban areas, allows to integrate also the causes of potential risk into the analysis); the factors subsequently considered are as follows:

a. accident classes, obtained by accounting accident typologies deduced by municipal police reports:

$a_{1}$. single vehicle, including both single vehicle run off the circulatory roadway and single vehicle loss of control at entry;

$\mathrm{a}_{2}$. entering-circulating accidents, including both head-on collisions and lateral collisions;

$\mathrm{a}_{3}$. accidents between vehicles on the same road element of the roundabout, including rear-end at entry and accidents due to come alongside at arms and in the circulatory roadway;

$\mathrm{a}_{4}$. accidents involving vulnerable users, including accidents implicating pedestrians and moped;

$\mathrm{a}_{5}$. others, including accidents with low frequency as those ones implicating impact against obstacles or due to chance circumstances (presence of road yard, temporary installations, spilling oily substances on the pavement, etc.).

b. accident causing factors, as follows:

$\mathrm{b}_{1}$. lane changing, being the cause of side collisions and accidents due to weaving in the circulatory roadway and at approaches;

$b_{2}$. improper driving behavior, for deviation of effective behavior from that prescribed; this typology includes both accidents due to non-observance of sign system (for example the right-of way at intersections), accidents due to unsuitable uses at the sides (especially the regulation of parking) and resulting interferences between trajectories of vehicles;

$b_{3}$. maintenance, including accidents due to degradation of road surface characteristics, bad visibility conditions of sign system, local restricted visibility because of obstacles and/or proliferated vegetation at the sides of the road, etc.;

$\mathrm{b}_{4}$. inadequate geometry (both at the approaches and along the circulatory roadway) directly accountable for single vehicle loss of control;

$b_{5}$. other accidents, enclosing accidents due to chance situations (for example road surface conditions) or, however not attributable to other categories. 
c. accident location, based on sharing the examined intersections into stretches composed by:

$\mathrm{c}_{1}$. approaches;

$\mathrm{c}_{2}$. changing lanes;

$\mathrm{c}_{3}$. arms;

d. types of users, distinguished as follows:

$\mathrm{d}_{1}$. cars;

$\mathrm{d}_{2}$. two wheelers;

$\mathrm{d}_{3}$. heavy vehicles;

$\mathrm{d}_{4}$. pedestrians;

$\mathrm{d}_{5}$. others;

e. traffic conditions:

$\mathrm{e}_{1}$. slow traffic;

$\mathrm{e}_{2}$. high traffic.

\subsection{Specificity of accident phenomenon}

The results of the aggregated accident analysis show some features of accident phenomenon specific for the examined circular intersections.

Figure 2 shows types of accident of the data sample; it's possible to observe that the more represented accident class (more than an accident over three) is consisting of accidents involving vehicles on the same element of the circular intersection; between these, accidents happening along the circulatory roadway are characterized by a relevant incidence, equal in percentage to accidents happening

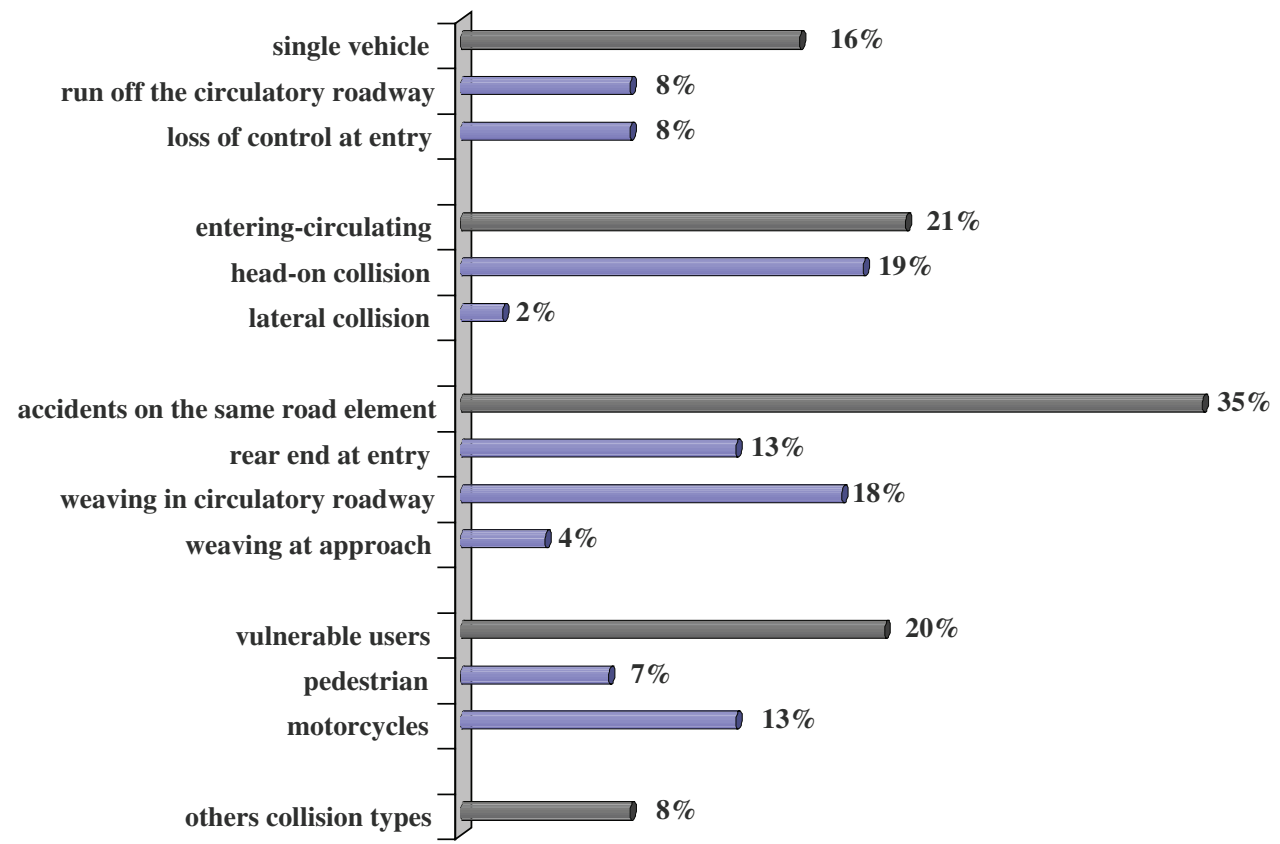

Figure 2: Types of sample accidents. 


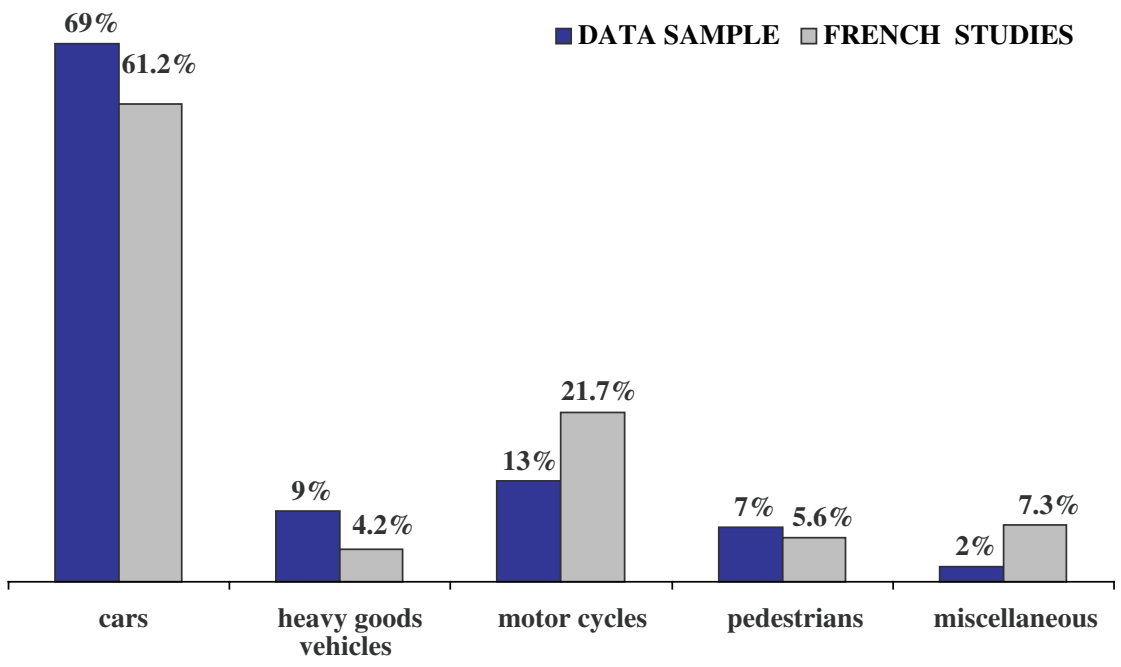

Figure 3: Types of users.

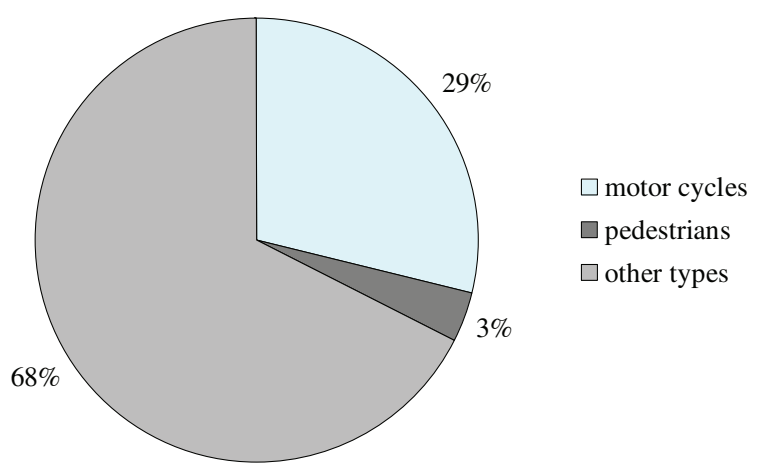

Figure 4: Mean percentage for vulnerable users at urban junctions in France [15].

at approaches or at arms. The class of entering-circulating accidents, if less than the previous one, represents a critical condition for the examined intersections.

Figure 3 shows that vulnerable users (pedestrians and two-wheelers) are particularly exposed to accident risk, both in absolute terms and as regards literature informations [15]. Moreover, the obtained results for vulnerable users have to be in relation to the accident scenarios involving this class of users in the whole municipal territory; the developed analysis has confirmed an over exposition for pedestrians, as well as it has highlighted for two-wheelers a percentage incidence definitely less than typical one happening at intersections. In fact, recent surveys carried out in the municipal territory of Palermo [16] show that 29 percent of accidents that happened at junctions involve two-wheelers; the percentage comes down to $3.4 \%$ for pedestrians (see Fig. 4).

Independently from the particular accident class, the risk level at intersections of the sample is more increased in slow traffic conditions due to lower restraints in speed (see Fig. 5). The accident localization shown in Fig. 6, along the stretches in which the examined intersections have been subdivided (approaches, changing lanes, arms), highlighted that higher concentration is along the 


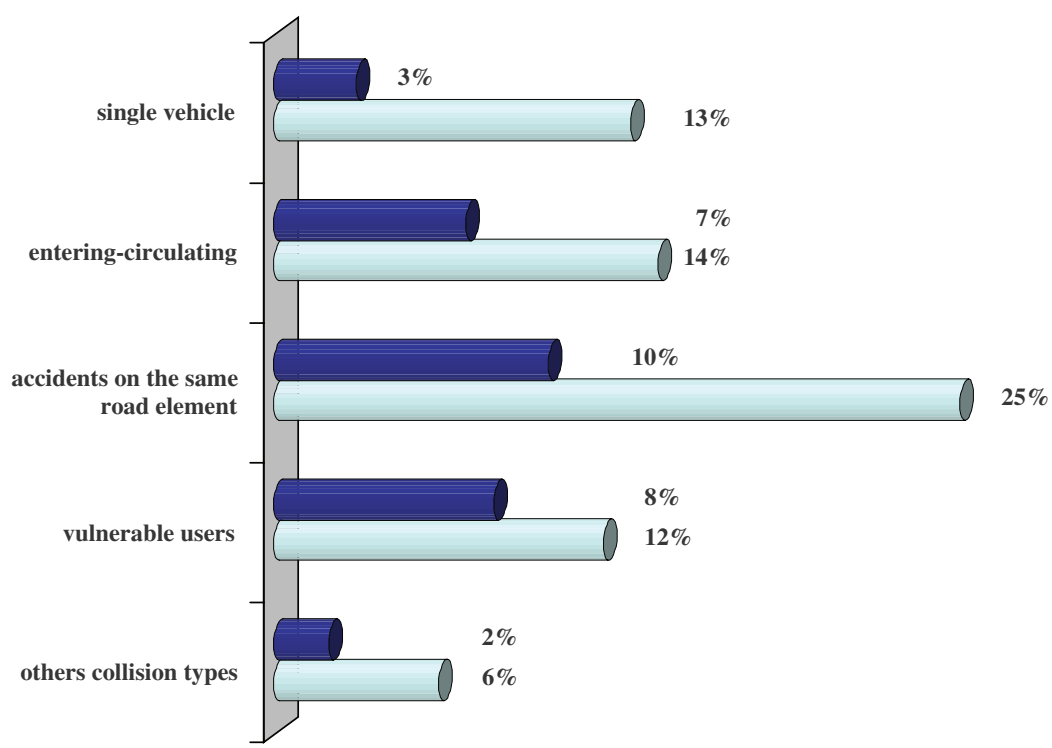

Figure 5: Types of accidents in different traffic conditions.

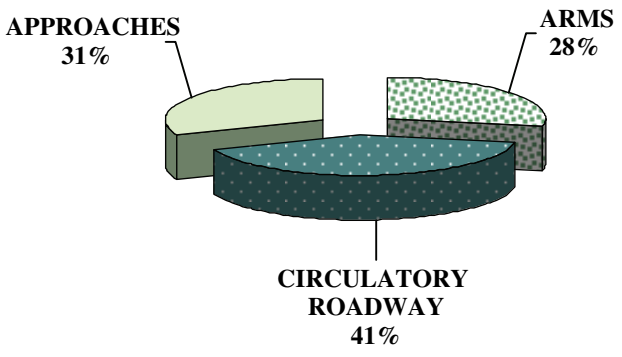

Figure 6: The accident localization.

circulatory roadway. This result has to be related to geometric design observed during site visits characterizing the different intersections and transversal sections of the circulatory roadway, more times with a variable width and/or not uniform number of lanes.

Figure 7 shows different types of more recurring accident factors. These accident factors, however the analysis level is able to underline, are prevalently referable (more than $40 \%$ ) to non-observance of prescribed rules (as regards both the component 'users in motion' and use of margins) and less, but even important, to other accident causing factors, expecially with reference to those referable to changing lane maneuvers.

It's significant that features highlighted above only partially reproduce the hierarchy of risk factors generally assumed for roundabouts; all this was to be expected considering the atypical characteristics of the examined intersections. The most accredited studies carried out in urban areas (see Table 1) actually show as dominant accident category (about $40 \%$ of accidents) the collision between entering and circulating vehicles and, at some distance, single vehicle accidents and accidents involving pedestrians. 


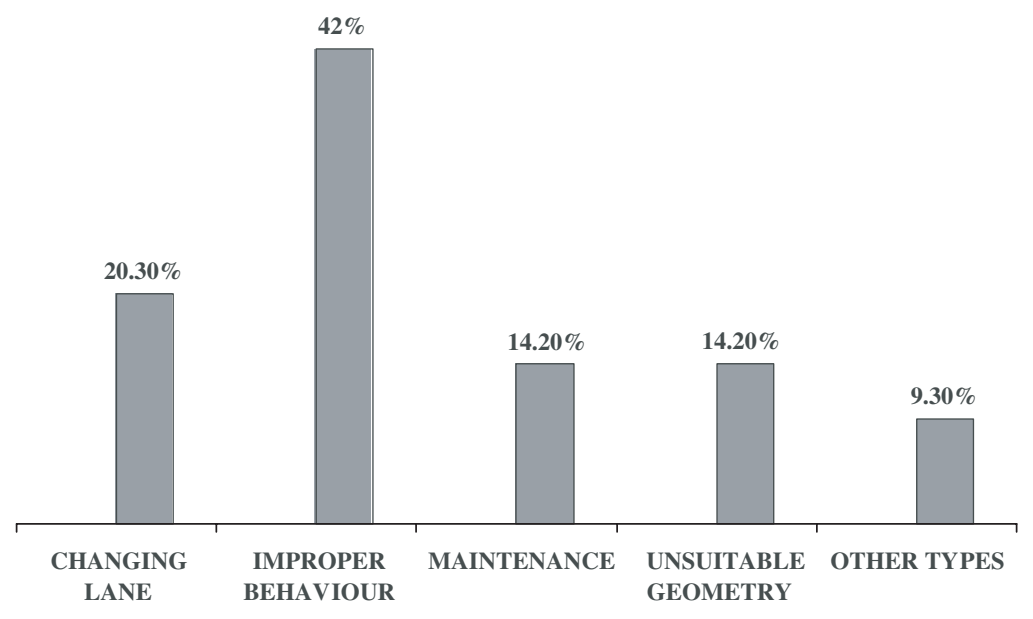

Figure 7: Accident causing factors.

Similarly, studies carried out in UK, for example the study of Maycock and Hall [17], confirm this indication for modern roundabouts, independently from the surrounding environment (urban, suburban, rural areas); for old roundabouts, together with this accident category (collision between entering and circulating vehicles), categories as loss of control and rear end at entry are equally represented. In the same way, as it's possible to deduce by above mentioned diagnostic studies, accidents that occurred in circulatory roadway are marginal for the slow highlighted frequency; on the contrary, in the case study, they have a very important role in the accident occurrence.

\section{RISK ANALYSIS BY MEANS OF AN INFRASTRUCTURAL SCENARIOS METHOD}

The atypicalness of the examined intersections, also confirmed by the results of aggregate analysis, suggested for the risk evaluation to apply to case studies an accident delocalization procedure [18] based on infrastructural scenarios recognizable at different intersections represented in the study sample.

The basic idea is that the accident phonomenon in similar road situations (scenarios), but in different examined intersections, reproduces whenever the same infrastructural scenario occurs. So the accidents can be grouped on 'scenario' factor and then, at least in relative terms, the accident levels - so determined and made independent of the original sites - can be assumend as a risk measure.

\subsection{The infrastructural scenarios}

Each intersection of the sample for defining the infrastructural scenarios has been examined in order to identify similar and recurring road situations, susceptible of performing the role of risk factors; this has resulted in the recognition of three critical basic situations:

- arms tangent to the circular intersection

- circulatory roadway elements between two consecutive arms characterized by short length

- entries with local restricted visibility conditions. 
Table 1: Peculiar features of the accident phenomenon at roundabouts.

\begin{tabular}{|c|c|}
\hline Accident type & Risk factors \\
\hline $\begin{array}{l}\text { Non-observance of giving way } \\
\text { to vehicles on the } \\
\text { circulatory roadway by } \\
\text { entering vehicles (likelihood = } \\
36 \% \text { ) }\end{array}$ & $\begin{array}{l}\text { - Tangent arms (or high bend radium at entry) } \\
\text { - Wide width at entry (and/or unsuitable number of lanes) } \\
\text { - High speed at entry } \\
\text { - Presence of oval central island } \\
\text { - Absence of traffic island at entry }\end{array}$ \\
\hline $\begin{array}{l}\text { Non-observance of giving way } \\
\text { to two-wheelers on the } \\
\text { circulatory roadway by } \\
\text { entering vehicles (likelihood = } \\
10 \% \text { ) }\end{array}$ & $\begin{array}{l}\text { - Tangent arms (or high bend radium at entry) } \\
\text { - Roundabouts with high outer radius as regards the } \\
\text { surrounding environment and the type of road } \\
\text { - Wide width at entry (and/or unsuitable number of lanes) } \\
\text { - High speed at entry } \\
\text { - Central island with small radius (or with oval shape) } \\
\text { - Absence of traffic island at entry } \\
\text { - Absence of canalization at roundabouts with Rest }>20 \mathrm{~m}\end{array}$ \\
\hline $\begin{array}{l}\text { Loss of control at entry } \\
(\text { likelihood }=11.4 \%)\end{array}$ & $\begin{array}{l}\text { - High speed at entry } \\
\text { - High slope of approaches } \\
\text { - Improper readability of installations and road signs } \\
\text { - Environment producing errors (recent installations) } \\
\text { - Absence of traffic island } \\
\text { - Fixed obstacles on the central island worsening the } \\
\text { accident consequences }\end{array}$ \\
\hline $\begin{array}{l}\text { Accident involving pedestrians } \\
(\text { likelihood }=10.4 \%)\end{array}$ & $\begin{array}{l}\text { - Wide width at entry/exit (or unsuitable number of lanes) } \\
\text { - Long pedestrian crossing and/or absence of traffic island } \\
\text { - Unsuitable location of pedestrian crossing } \\
\text { - Absence of traffic island }\end{array}$ \\
\hline $\begin{array}{l}\text { Loss of control at entry for two } \\
\text { wheelers (likelihood }=2 \% \text { ) }\end{array}$ & $\begin{array}{l}\text { - High speed at entry } \\
\text { - Slippery road } \\
\text { - Oval central island }\end{array}$ \\
\hline
\end{tabular}

Moreover, the possible presence of interferences at the sides, then identified as very critical factor, has been considered and the risk analysis has been developed as reagards six main scenarios obtained combining the last factor to the three above mentioned critical basic situations.

Based on the results of the aggregate analysis before shown, as well as the results obtained through field observations related to geometric features and specific operational conditions, a preliminary risk evaluation for the different scenarios has been carried out combining to each scenario one or more accident causing factors ( $a c f s$ ); in order to explain the risk level of each scenario, the $a c f s$ referable to the geometric data have been classed into three main categories, each one established as regards deviation from best conditions of one of three elements:

a. geometry at the approaches (entry curvature, entry width, entry angle, etc.);

b. local geometric anomalies, depending on design characteristics (circulatory roadway width, short length of changing lanes) and on traffic (longitudinal slope of arms and visibility conditions);

c. uses at the sides, especially as regards the regulation of parking or the presence of private accesses at the approaches and along the circulatory roadway. 
Table 2: Responsibilities of accident causing factors.

\begin{tabular}{|c|c|c|c|}
\hline \multirow[b]{2}{*}{ Infrastructural scenarios } & \multicolumn{3}{|c|}{ acfs } \\
\hline & A & B & $\mathrm{C}$ \\
\hline 1. Arms tangent to the circular intersection & $\bullet$ & - & - \\
\hline 2. Arms tangent to the circular intersection with interferences at the sides & $\bullet$ & - & $\bullet$ \\
\hline $\begin{array}{l}\text { 3. Circulatory roadway elements between two consecutive arms characterized } \\
\text { by short length }\end{array}$ & - & $\bullet$ & - \\
\hline $\begin{array}{l}\text { 4. Circulatory roadway elements between two consecutive arms characterized } \\
\text { by short length with interferences at the sides }\end{array}$ & - & $\bullet$ & $\bullet$ \\
\hline 5. Entries with local restricted visibility conditions & - & • & - \\
\hline $\begin{array}{l}\text { 6. Entries with local restricted visibility conditions with interferences at the } \\
\text { sides }\end{array}$ & - & $\bullet$ & • \\
\hline
\end{tabular}

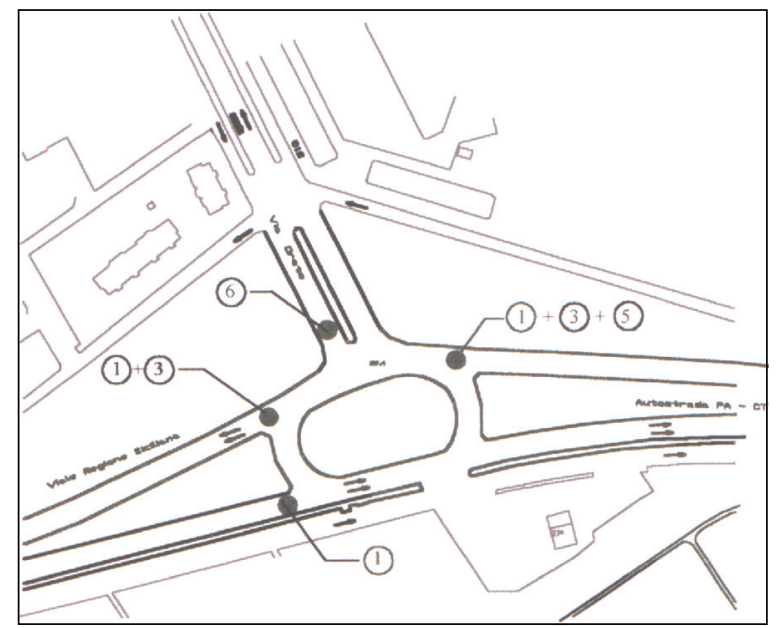

Figure 8: Example for the graphical depiction of infrastructural scenarios.

See Table 2 for the qualitative contribution of the different acfs and the risk level related to each scenario.

\subsection{The risk model: quantitative analysis}

The risk analysis by means of an infrastructural scenarios method, based on accidents delocalization procedure, has been checked considering globally occurred aggregate accidents in order to deduce the levels of responsibility of the different acfs in determining the risk of accidents and to evaluate road use safety as a function of the systemic characteristics of the intersection. As regards globally occurred aggregate accidents, first the analysis of the intrinsic characteristics of each intersection has been carried out to identify the actual infrastructural scenarios and their frequency (see the example in Fig. 8); then, the disaggregation of accidents of each intersection to each scenario (see Table 3) and, last, the evaluation of the risk related to each infrastructural scenario have been made. 


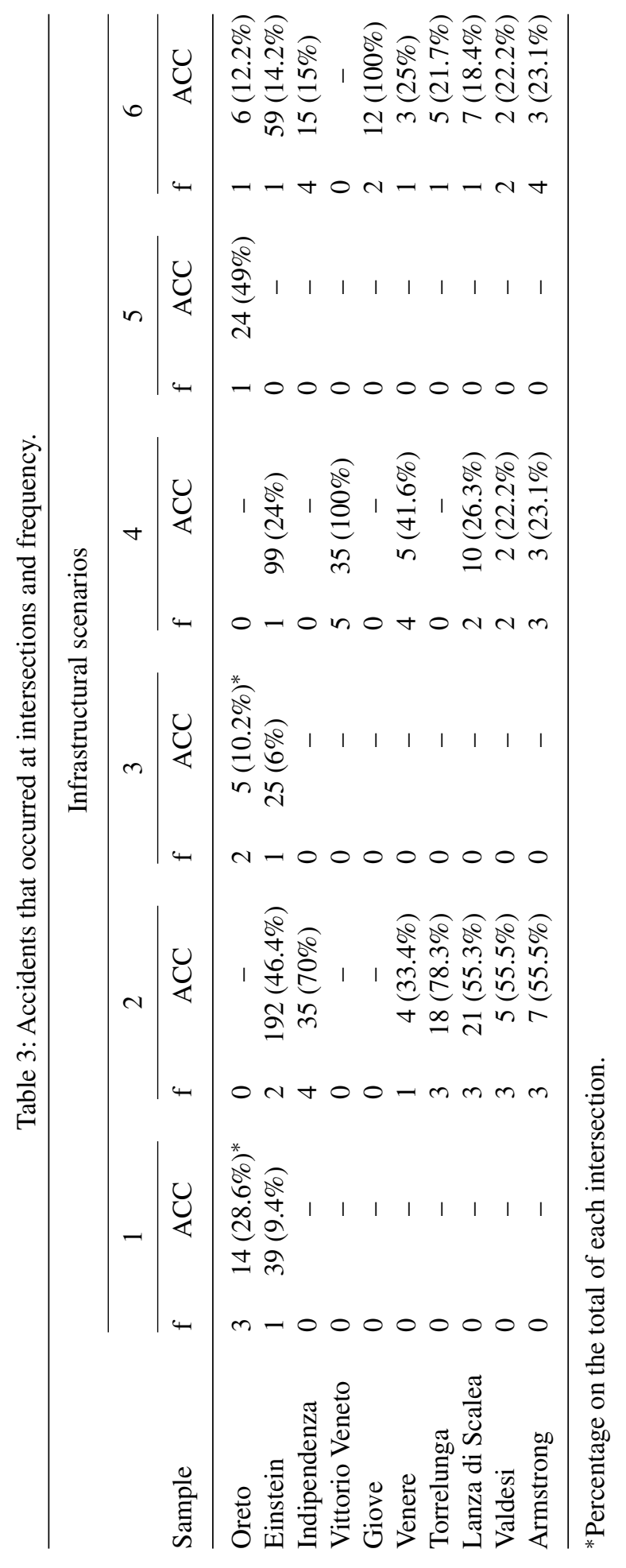


The vector $[\underline{\mathbf{R}}]$ has allowed the relative evaluation of risk; each element is the risk linked to each infrastructural scenario, expressed as regards strength of the accident phenomenon observed for the whole sample.

Based on the different risk exposure characterizing intersections of the sample and the influence exerted on the accident phenomenon, the examined circular intersections were taken to an equivalent traffic condition, in order to establish homogeneous terms of comparison to value the risk levels observable in different traffic and risk exposure conditions.

For this purpose, the homogenization coefficients $\alpha_{j(j=1,2, \ldots, 10)}$ related to each $j_{(j=1,2, \ldots 10)}$ intersection of the sample have been defined, based on crash prediction equations proposed in the literature [17] between accidents $(A)$ and total entering traffic $(Q)$ :

$$
A_{i j}=k \cdot(Q)^{\beta}
$$

The coefficients ( $k$ and $\beta$ ) of the above-mentioned equation were checked in relation to the circular intersections of the sample, obtaining a good agree of data considering both global accidents and personal injury accidents (see Table 4).

For the intersection characterized by the highest entering traffic flow $\left(\mathrm{Q}_{\max }\right)$, the number of expected accidents $\left(\mathrm{A}_{j}{ }^{*}\right)$ can be computed as follows:

$$
A_{j}^{*}=k \cdot\left(Q_{\max }\right)^{\beta}
$$

The homogenization coefficients of the generic intersection of the sample (see Table 5$)-$ if $1 / \alpha_{j}=$ 1 for the intersection characterized by the highest traffic flow $\left(Q_{\max }\right)$ - can be computed considering $\left(Q_{\max } / Q_{j}\right) \beta$ ratios, as follows:

$$
\frac{1}{\alpha_{j}}=\frac{A_{j}^{*}}{A_{j}}=\left(\frac{Q_{\max }}{Q_{j}}\right)^{\beta}
$$

Table 4: Prediction equations accidents-entering daily traffic (veic $\times 10^{3}$ ).

\begin{tabular}{lll}
\hline Global accidents & $y=1.624 \cdot x^{0.9398}$ & $R^{2}=0.6239$ \\
Personal injury accidents & $y=0.9699 \cdot x^{0.8971}$ & $R^{2}=0.6586$
\end{tabular}

Table 5: Homogenization coefficients $(\beta=0.9398)$.

\begin{tabular}{lcc}
\hline Intersection & $Q_{\max } / Q_{j}$ & $1 / \alpha_{j}$ \\
\hline Oreto & 1 & 1 \\
Einstein & 1.046972152 & 1.044083026 \\
Indipendenza & 2.889865845 & 2.711020775 \\
Vittorio Veneto & 3.683109982 & 3.40508975 \\
Giove & 19.34526699 & 16.18538108 \\
Venere & 4.938197026 & 4.485548895 \\
Torrelunga & 5.66068892 & 5.099722655 \\
Lanza di Scalea & 6.479878049 & 5.790425912 \\
Valdesi & 12.77283654 & 10.9569292 \\
Armstrong & 4.877753978 & 4.433932265 \\
\hline
\end{tabular}


The homogenization coefficients, shown in eqn (3), valid for the accidents of the same $i$ infrastructural scenario, can be computed as follows:

$$
A_{i j}^{*}=\frac{A_{i j}}{\alpha_{i j}} .
$$

Therefore, disaggregated accidents by a delocalization procedure and grouped to the infrastructural scenarios, the elements of the vector $[\mathbf{R}]$ are, in homogeneous terms (because they were taken back to an equivalent traffic condition), the relative hierarchy of risk levels characterizing the infrastructural scenarios at the different circular intersections of the sample. So $[\underline{\mathbf{R}}]$ can now be computed as follows:

$$
[\underline{\mathrm{R}}]=\left(R_{i}\right)_{i=1,2 \ldots, n}=10^{2} \cdot\left[\frac{\sum_{j=1}^{m}\left(\frac{A_{i j}}{\alpha_{j}}\right)}{\sum_{i=1}^{n} \sum_{j=1}^{m}\left(\frac{A_{i j}}{\alpha_{j}}\right)}\right]_{i=1, \ldots, n},
$$

where

- $A_{i j}=$ accidents related to $i(i=1,2, \ldots, n)$ infrastructural scenario at the $j(j=1,2, \ldots, m)$ circular intersection;

- $A_{i j} / \alpha_{j}=$ homogenized accidents with reference to the highest entering traffic flow $\left(Q_{\max }\right)$;

- $1 / \alpha_{j}=$ homogenization coefficients for the accident level $\mathrm{A}_{i j}$ related to $i(i=1,2, \ldots, n)$ infrastructural scenario at the $j(j=1,2, \ldots, m)$ circular intersection (see Table 5).

Considering the random character of accident phenomenon, each element of the vector $\underline{R}$, as shown in eqn (5), is associated to a confidence interval within which, at an established probability level, the real mean value $\left(r_{i}\right)$ is set. This interval depends both on size of data sample, as from which the estimate of $R_{i}$ has been carried out, and on distribution of probability it belongs to:

$$
R_{i}-z_{c} \cdot \sigma<r_{i}<R_{i}+z_{c} \cdot \sigma,
$$

where $z_{c}$ is the critical value of the distribution at the desired confidence level. In the case of binomial distribution, as from the randomness of accident phenomenon is usually interpreted, the mean square deviation, based on sample data, can be computed as follows:

$$
\sigma=\sqrt{\frac{R_{i}\left(1-R_{i}\right)}{n}},
$$

where $n$ is equal to the number of observations belonging to the sample; the expression shown in eqn (6) can be considered sound for $n \geq 30$.

\section{RESULTS OF THE ANALYSIS}

The relative risk joined to the examined infrastructural scenarios is shown in Figure 9, where the trust limits at the confidence level of 90 percent are indicated, too. The reliability of results (i.e. the risk hierarchy between the different infrastructural scenarios) keeps also for a confidence level of 95 percent. As shown, the obtained results, important from the statistical point of view in most case, allow to define a marked hierarchic order between different scenarios; a biased overlapping of confidence intervals for scenarios 3 and 5 , on the contrary leads to consider them as equivalent from the risk point of view. As well, the analysis of results allows us to conclude that the presence of interferences 


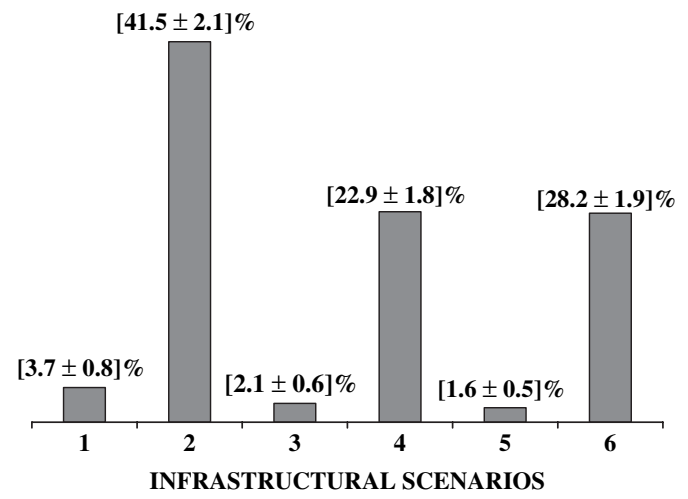

Figure 9: Risk levels of infrastructural scenarios.

at the sides operates as an aggravating factor of risk conditions, though this is differentiated for the different base scenarios:

- the presence of arms tangent to the circular intersection (scenario 1), due to behaviors suggested by this situation (high entering speeds or, however, inconsistent with the functional scheme of intersections; non-observance of the right of way, etc.), proves to be a risk factor of primary importance, even though in absence of interferences; it becomes specially dangerous due an improper use of sides (scenario 2);

- local restricted visibility conditions at entries, in absence of interferences, stimulating a more prudent behavior, reduce the likelihood of accidents (scenario 5); on the contrary, an unexpected emergency at sides (scenario 6) proves specially dangerous, also comparable to other examined accidents;

- differing from literature reports, the result of analysis shows again a quite critical situation as compared to other scenarios for circulatory roadway elements between two consecutive arms characterized by short length; this circumstance has to be related to specific features of roundabouts of the sample $(D>30 \mathrm{~m})$ and to consequent operational conditions. Possible interferences at sides (scenario 4) worsen the risk of this scenario, even though less than what is observed at the other scenarios.

\section{CONCLUSIONS}

From the methodological point of view, the broad application of the principle of accident delocalization, on which the proposed analysis method is based, has allowed to highlight, even though in relative terms, the riskiness of different infrastructural scenarios composing circular intersections. At the same time, the results of this study show the bent of the used indicator for expressing, in homegeneus terms and so useful in the comparison, the risk levels corresponding with observed accident events, as well as what happens in quite different traffic conditions .

From the application point of view, consistently with preliminary remarks, the risk analysis by means of an infrastructural scenarios method proves reliable whereas urban road schemes are characterized by peculiar geometric features such that the application of the safety methods proposed in the literature and obtained from layouts only partially comparable to the examined ones is not posiible. In this case, the risk analysis by means of an infrastructural scenarios method allows to determine terms of comparison absolutely necessary in order to carry out a road safety preventive evaluation independent of the accident phenomenon analysis; the last one, in fact, is based on the analogy 
between the examined installation and scenarios, for which causing factors and type of accidents aren't known, allowing the risk evaluation through real observations of road environment and driver behavior, without any information about accidents that have already occurred.

Moreover, in safety studies, the proposed methodology is a reliable tool for the diagnostic examination of accidents with poor information (for example, in presence of installations characterized by slow traffic, in presence of fragmentary data or related to a little space); as regards this matter, together with the advantages that the accident delocalization allows to obtain (the consistency of data, the proposed risk indicator, that is independent of the traffic variable, and of its effects on the intensity of the phenomenon) it also allows us to determine, in homogeneus terms, a comparison between the accident levels of the different examined scenarios (and the different observed road installations) and to carry out the risk evaluation in a hierarical relative scale.

After applying the proposed approach the issues to be assessed before introducing engineering countermeasures into existing road infrastructural schemes or new road installations are known. This is consistent with the needs of decision support tools useful for identifying preventive evaluation issues for road safety measures that are in the same time measure of sustainable mobility. This is why improving road safety contributes to guarantee sustainable traffic conditions.

The approach, derived from explicit considerations about the importance of the definition of supportive tools for identifying the risk level for road schemes for which traditional studies aren't able to foresee safety conditions due to the atypical configuration they take on, is able to define the safety issues of new policy instruments and to address the scenarios that need to be tested.

Furthermore this approach, allowing the incorporation of risk evaluations during design and development of technical measures, is able to provide useful information for policymakers and designers as regards the choices relating to the priorities of intervention in order to improve road safety and then the sustainability of traffic system at differen levels.

\section{ACKNOWLEDGMENT}

I'd like to express my own thanks to Prof. O. Giuffrè for the suggestions offered during the progress of this research.

\section{REFERENCES}

[1] Sustainable mobility: 2000-2004 action programme, Communication from the Commission to the Council, the European Parliament, the Economic and Social Committee and the Committee of the Regions on the common transport policy - 'Sustainable mobility: perspectives for the future'. COM (1998) 716 Final report. available at: http://europa.eu.int.

[2] Defining an environmentally sustainable transport system. Commission Expert Group on Transport and Environment (WGI), Final report. 6 September 2000.

[3] White Paper: 'European transport policy for 2010: time to decide' [COM (2001) 370 Final report submitted by the Commission on 12 September 2001.

[4] European Road Safety Action Programme. Communication from the commission COM (2003) 311 Final report. Brussels, 2 June.2003.

[5] Road Directorate, Manual of Road Safety Audit. Ministry of Transport, Denmark, 1994.

[6] University of New Brunswick, Road Safety Audit Guidelines, UNB Transportation Group, 1999.

[7] Public Work Department, Guidelines for the Road safety audit of roads and road projects in Malaysia. Malaysia, 1999.

[8] 'Linee guida per le analisi di sicurezza delle strade'. Circolare del Ministero LL.PP - Ispettorato Generale per la Circolazione e la Sicurezza Stradale - n. 3699 del 08/06/01). 
[9] Jagtman, H.M., The traffic Hazop: a method for identifying deviations from the desired operations in road traffic. Svow Colloquium. TU Delft, June 2002.

[10] CETUR, Conception des carrefours à sens giratoires implantés en milieu urbain, 1988.

[11] Guichet, B., Typologie des accidents dans le giratoires urbaines, Centre d'Etudes Techniques de l'Equipment de l'Ouest Nantes (France). CETUR-SETRA, 1993.

[12] Da Rios, G. \& Rinelli, S., Contributo all' analisi sistemica dei fattori di rischio nelle intersezioni stradali. Proc. of the X Convegno S.I.I.V. (CD-ROM), Catania, 2000.

[13] CETUR, Carrefours urbains: Aménagement et exploitation de la voire, Collection du CETUR, 1999.

[14] Brenac, T., Carrefours giratoires en France: evolutions, niveau de securitè, Salon de Provence (France): Institute Nationale de Recerche sur le Transport et leur securite -CETUR/SETRA, 1993.

[15] Alphand, F., Noelle, U. \& Guichet, B., Roundabouts and Road Safety: State of the Art in France. CETUR/SETRA, 1991.

[16] Grammatico, P., Incidentalità in ambito urbano, $\mathrm{PhD}$ thesis in Road Infrastrucure Engineering (X Ciclo), Palermo University, 1999.

[17] Maycock, G. \& Hall, R.D., Accidents at 4-arm roundabout. TRRL, Southampton University, 1984.

[18] Fleury, D., Fline C. \& Peytauin, J.F. (eds), La diagnostic locale de sècuritè, outils et methods. INRETS, ed. SETRA, 1991. 